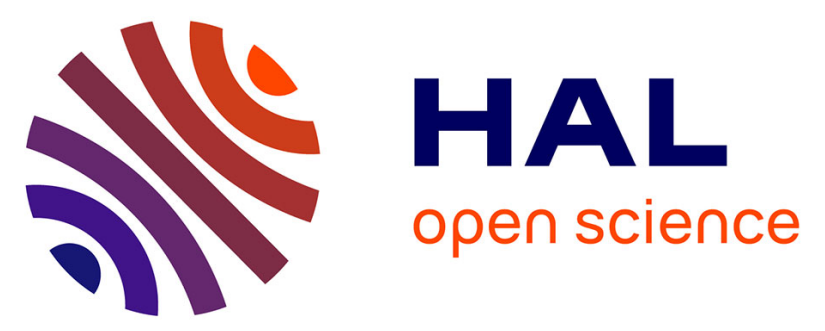

\title{
Comparison between a Double Excitation Synchronous Machine and a Permanent Magnet Synchronous Machine According to Various Constant Power Speed Ranges
} Trung-Kien Hoang, M. Gabsi, L Vido, F Gillon

\section{- To cite this version:}

Trung-Kien Hoang, M. Gabsi, L Vido, F Gillon. Comparison between a Double Excitation Synchronous Machine and a Permanent Magnet Synchronous Machine According to Various Constant Power Speed Ranges. EVER, Apr 2017, Monaco, Monaco. hal-01657379

\author{
HAL Id: hal-01657379 \\ https://hal.science/hal-01657379
}

Submitted on 6 Dec 2017

HAL is a multi-disciplinary open access archive for the deposit and dissemination of scientific research documents, whether they are published or not. The documents may come from teaching and research institutions in France or abroad, or from public or private research centers.
L'archive ouverte pluridisciplinaire HAL, est destinée au dépôt et à la diffusion de documents scientifiques de niveau recherche, publiés ou non, émanant des établissements d'enseignement et de recherche français ou étrangers, des laboratoires publics ou privés. 


\section{Comparison between a Double Excitation Synchronous Machine and a Permanent Magnet Synchronous Machine According to Various Constant Power Speed Ranges}

\author{
K. Hoang and M. Gabsi \\ SATIE, ENS Cachan \\ 94235 Cachan, France \\ Email: kienht26@gmail.com \\ gabsi@satie.ens-cachan.fr
}

\author{
L. Vido \\ SATIE, Universite de Cergy Pontoise \\ 95000 Cergy-Pontoise, France \\ Email: lionel.vido@u-cergy.fr
}

\author{
F. Gillon \\ L2EP, Ecole Centrale de Lille \\ 59650 Villeneuve d'Ascq Cedex, France \\ Email: frederic.gillon@ec-lille.fr
}

\begin{abstract}
This paper presents a comparison between a Double Excitation Synchronous Machine (DESM) and a Permanent Magnet Synchronous Machine (PMSM). Optimal designs of both machine types are compared regarding different constant power speed ranges (CPSR). The optimization objectives are to minimize the active material cost and losses. Results show that the DESM is more advantageous over the PMSM counterpart in loss saving at a wide CPSR, and the PMSM is capable of reducing the machine cost.
\end{abstract}

Index Terms-Constant power speed range, double excitation, electric vehicle, optimization.

\section{INTRODUCTION}

A Double (or hybrid) Excitation Synchronous Machine (DESM) is constructed based on a combination between a permanent magnet synchronous machine (PMSM) and additional field windings [1]-[3]. The purpose behind is to bring together advantages of a PMSM, which are high power density and high efficiency, and a good capability in air-gap flux control of a wound field synchronous machine. This advantage seems to make the double excitation machine type a very interesting candidate for transportation applications, where variable speeds are usually required. Having a machine using additional field windings, however, would result in a complex geometry, and performances of existing permanent magnets (PMs) might be weakened in certain prototypes [4]. In addition, using field windings is an effective solution to reduce the air-gap flux. However, at the same time a torque reduction would occur. Therefore, the air-gap flux control in a double excitation machine is a complex issue. Specific comparisons between DESM and PMSM types according to different prototypes and applications will help designers have a proper design. To the authors' knowledge, unfortunately, such comparisons seems to be scarce in the literature, even though there has been massive research efforts for each machine type in transportation applications, such as [5]-[8] for PMSMs, and [9]-[11] for DESMs.

This paper aims at comparing a DESM and a PMSM according to various ranges of speed. The main reason behind is to target directly the flux controlling capability, which is claimed to be the key feature of a double excitation machine. The comparison result is expected to give a base to decide in which circumstances, using DESMs is more beneficial over the PMSM counterparts regarding the machine cost and losses.

Aiming at a fair comparison, the PMSM model is derived by removing some parts from the DESM. Optimal designs of both machine types are compared by using multi-physics models. The objectives are to minimize the active material cost and total losses at the base and maximum speeds. The work is organized as follows: Section II presents a multi-physics model that mainly contains a coupling between electromagnetic and thermal models. Section III addresses the optimization approach.. Section IV analyses the comparison results followed by a conclusion.

\section{MULTI-PHYSICS MODEL}

The DESM prototype is shown in Fig. 1(a) [12] with two global field windings. The corresponding permanent magnet type is displayed in Fig. 1(b) by removing some parts from the DESM model. Machine parameters 
are detailed in the appendix section. Flux paths in the DESM model are truly three dimensional (3-D) at some positions; therefore, the 3-D finite element method (FEM) is usaully required to obtain highly accurate results. This method, however, substantially increases the computation time, and it is not practical for the optimization process. In this paper, the electromagnetic model is performed by a generalized equivalent magnetic circuit network (EMCN), which is detailed in [13]. The thermal model is accomplished by using a lumped parameter thermal network. In order to more accurately calculate the total losses, mechanical and inverter losses are also computed.

\section{A. Mechanical and inverter losses}

1) Mechanical model: Two types mechanical losses presented in an electrical machine are the windage loss in the air gap, which is due to the rotor's rotation, and the friction losses in the bearings. A proper calculation of these losses not only help designers have a more accurate value of machine's efficiency but also provide heat sources input to the thermal model. According to [14], the windage loss of a cylinder rotating in a concentric cylinder is computed based on the following assumptions: No axial flow exists, the gap is small compared to the radius and axial length, and the air in the gap is homogeneous.

With those assumptions, the windage loss is calculated as (1):

$$
W_{\text {windage }}=\pi C_{d} \rho R^{4} \omega^{3} L
$$

where $\rho$ is air density in the air gap $\left[\mathrm{kg} / \mathrm{m}^{3}\right], R$ is average air-gap diameter $[\mathrm{m}], \omega$ is rotor angle speed $[\mathrm{rad} / \mathrm{s}], L$ is axial length [m], and $C_{d}$ is skin friction coefficient.

The friction coefficient $C_{d}$ is defined as (2a) for the laminar flow, and (2b) for the transition and turbulence cases.

$$
\begin{aligned}
C_{d} & =\frac{2}{R_{e}} \\
\frac{1}{\sqrt{C_{d}}} & =2.04+1.768 \cdot \ln \left(R_{e} \sqrt{C_{d}}\right)
\end{aligned}
$$

In a rotating machine, two bearings are usually located at the driving and non-driving ends. The friction losses in the bearings is apparently subject to rotor's properties (the rotating speed and rotor weight) and bearing's properties (the bearing size and friction coefficient). With a bearing using lubricant oil, after a certain time in use, the friction coefficient increases due to the lubricant oil deterioration. It is, therefore, complicated to obtain an accurate calculation of this friction loss. According to SKF (a bearing manufacturer), the bearing friction losses can be computed by (3):

$$
W_{\text {bearing }}=0.525 \cdot 10^{-4} \mu P d n
$$

where $\mu$ is friction coefficient, $P$ is equivalent dynamic bearing load [N], $d$ is bearing diameter [mm], and $n$ is rotating speed [rpm].

2) Power electronics model: The three-phase inverter topology using pulse width modulation (PWM) is shown in Fig. 2.

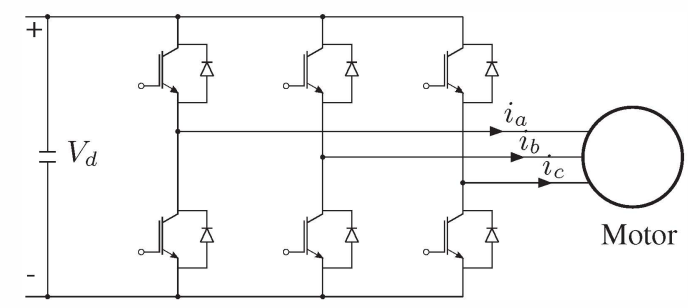

Fig. 2. Three phase inverter topology

The calculations of the inverter losses are fundamentally based on the sinusoidal load current assumption. Moreover, a linearized loss model is assumed. The switching loss energies $E_{s}$ is linearized given by (4a), and the conduction losses $P_{c}$ for a single semiconductor is calculated by (4b) [15].

$$
\begin{aligned}
& E_{s}=E_{s r} \cdot \frac{V_{v}}{V_{r e f}} \cdot \frac{i_{v}}{i_{r e f}} \\
& P_{c}=V_{0} \cdot i_{v}+r \cdot i_{v}^{2}
\end{aligned}
$$

where:

$E_{s r}$ is rated switching loss energy given for the reference commutation voltage and current $V_{\text {ref }}$ and $i_{\text {ref }}$

$V_{v}$ and $i_{v}$ indicate the actual commutation voltage and current, respectively

$V_{0}$ and $r$ are semiconductors threshold voltage and differential resistance, respectively.

The conduction loss in each IGBT and each freewheeling diode are expressed by (5a) and (5b), respectively.

$$
\begin{gathered}
P_{\text {con }, \mathrm{I}}=\frac{V_{\mathrm{CE}} \hat{i}_{L}}{2 \pi}\left(1+\frac{\pi A}{4}\right)+\frac{r_{\mathrm{CE}} \hat{i}_{L}^{2}}{2 \pi}\left(\frac{\pi}{4}+\frac{2 A}{3}\right) \\
P_{\text {con }, \mathrm{D}}=\frac{V_{\mathrm{F}} \hat{i}_{L}}{2 \pi}\left(1-\frac{\pi A}{4}\right)+\frac{r_{\mathrm{F}} \hat{i}_{L}^{2}}{2 \pi}\left(\frac{\pi}{4}-\frac{2 A}{3}\right)
\end{gathered}
$$

where:

$\hat{i}_{L}$ : peak load current

$A=M \cos \phi, M$ is modulation index, and $\phi$ is the displacement angle between the load current and the fundamental component of the phase voltage $V_{\mathrm{CE}}, r_{\mathrm{CE}}$ and $V_{\mathrm{F}}, r_{\mathrm{F}}$ : threshold voltages and differential resistances of the IGBT and diode, respectively.

The current supply principle for a field winding is shown in Fig. 3. 


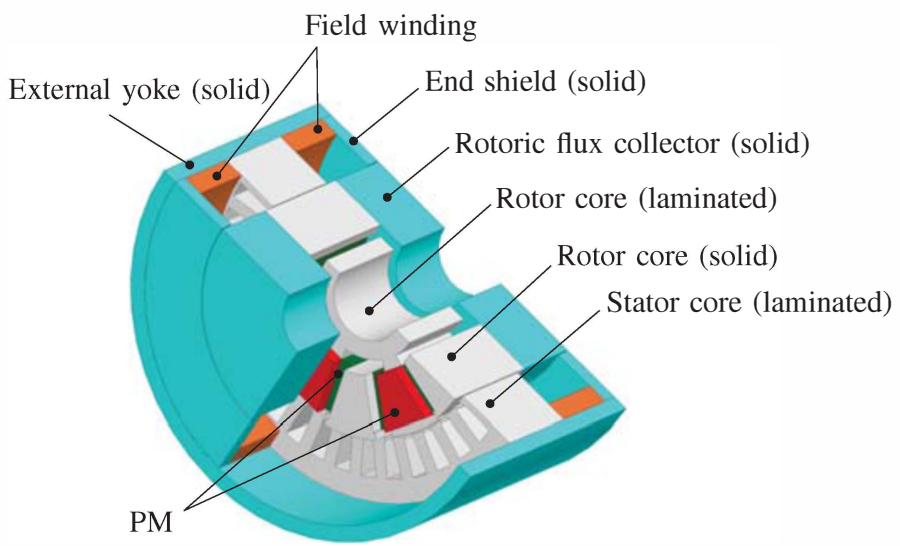

(a)

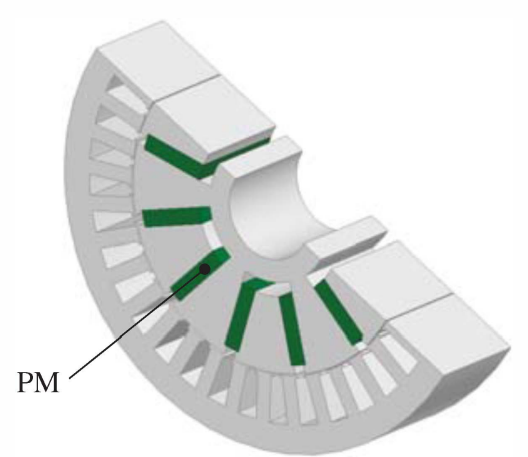

(b)

Fig. 1. Machines for comparisons. (a) DESM model. (b) Corresponding PMSM model

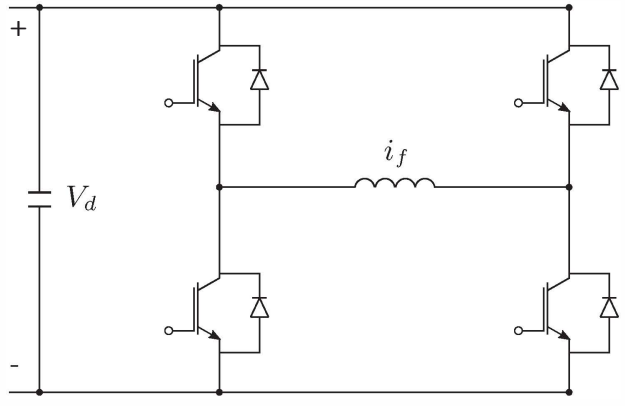

Fig. 3. DC-DC converter for field windings

The switching losses of the MOSFET and diode are expressed by (6a) and (6b), respectively.

$$
\begin{aligned}
& P_{\mathrm{sw}, \mathrm{MOSFET}}=\left(E_{\mathrm{On}}+E_{\mathrm{Off}}\right) \cdot f_{s} \\
& P_{\mathrm{sw}, \text { diode }}=Q_{r r} \cdot V_{d} \cdot f_{s}
\end{aligned}
$$

where $E_{\mathrm{On}}$ and $E_{\mathrm{Off}}$ are on and off switching energies of the MOSFET, $f_{s}$ is switching frequency, $Q_{r r}$ is reverse recovery charge, and $V_{d}$ is knee voltage of the diode.

The conduction losses of the MOSFET and diode are expressed by (7a) and (7b), respectively.

$$
\begin{aligned}
& P_{\mathrm{Con}, \mathrm{MOSFET}}=r_{\mathrm{CE}} \cdot I_{\mathrm{S}, \mathrm{rms}}^{2} \\
& P_{\mathrm{Con}, \text { Diode }}=r_{\mathrm{F}} \cdot I_{\mathrm{D}, \mathrm{rms}}^{2}+V_{\mathrm{F}, 0} \cdot(1-D) i_{f}
\end{aligned}
$$

where $r_{\mathrm{CE}}$ and $r_{\mathrm{F}}$ are differential resistance of the MOSFET, $I_{\mathrm{S}, \mathrm{rms}}$ is rms value of current flowing through the MOSFET, $D$ is duty cycle, and $V_{\mathrm{F}, 0}$ is threshold voltage of the diode.

\section{B. Lumped parameter thermal network analysis}

A lumped parameter thermal model is to benefit from the fast computation while maintaining a good accuracy for overall temperatures. The thermal network is shown in Fig. 4, which is capable of considering the transient process by introducing thermal heat capacitors.

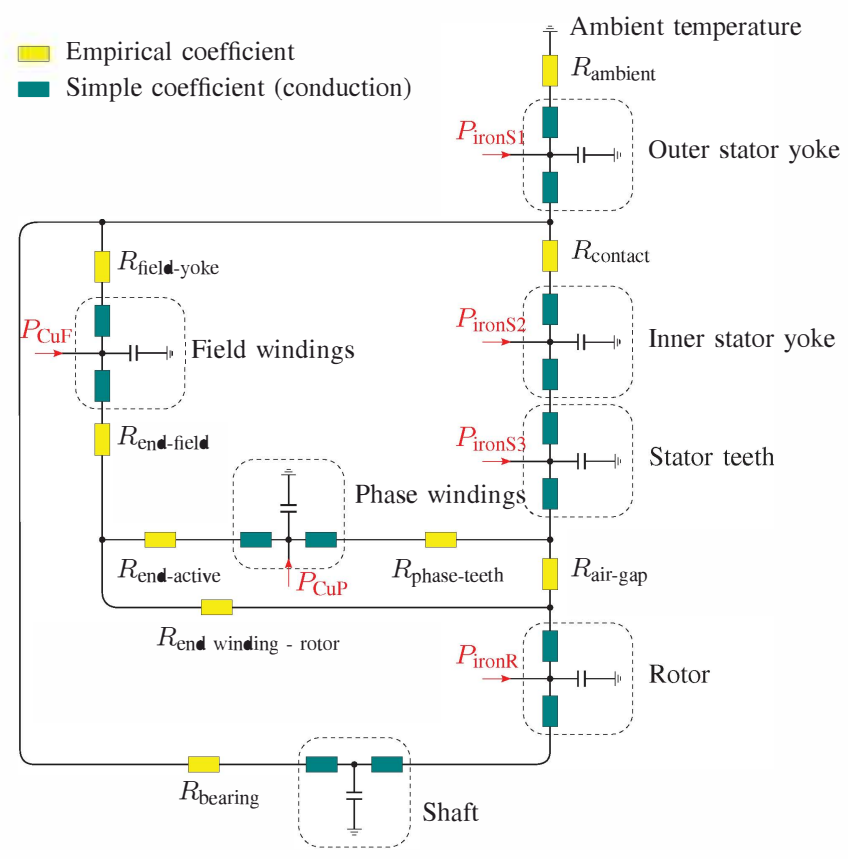

Fig. 4. Thermal network. Thermal resistances: $R_{\text {field-yoke }}-$ between field winding and outer stator yoke, $R_{\text {end-field }}$ - between armature end and field windings, $R_{\text {end-active }}$ - between armature end and active parts, $R_{\text {end-rotor }}$ - between armature end winding and rotor surface, $R_{\text {phase-teeth }}$ - between armature active winding and stator teeth, $R_{\text {air-gap }}$ - air gap, $R_{\text {bearing }}$ - bearing. Losses: $P_{\mathrm{CuF}}$ - field winding copper losses, $P_{\mathrm{CuP}}$ - armature copper loss, $P_{\text {irons1 }}$ - outer stator yoke core loss, $P_{\text {irons2 }}$ - inner stator yoke core loss, $P_{\text {irons } 3}$ - stator teeth core loss, $P_{\text {ironR }}$ rotor core loss

As it can be seen in Fig. 4, two types of thermal resistance are presented: one uses a simple coefficient, and the others need empirical coefficients. The first type can be easily computed based on the object geometry, while the second one is more challenging, and the coefficients based on experiments or design experiences are usually required. All of thermal coefficients and experimental validations are detailed in [4]. 


\section{OPTIMIZATION APPROACH}

\section{A. Optimization problem formulation}

The optimization objectives are to minimize the machine's active material and the total losses at two operating points, which are the base $\left(\Omega_{b}\right)$ and maximum $\left(\Omega_{m}\right)$ speeds. $\Omega_{m}$ is actually the maximum achievable speed. At this speed, the produced torque should be close to zero as shown in Fig. 5.

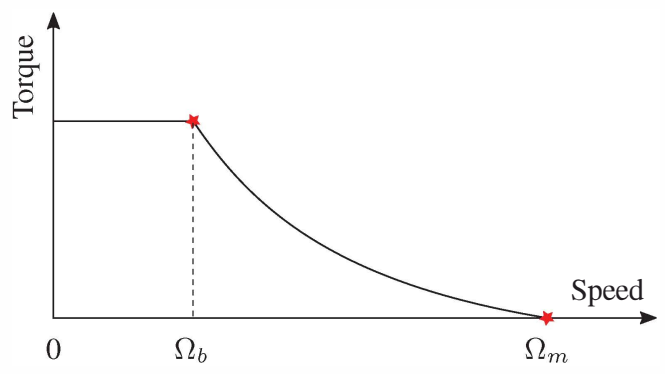

Fig. 5. Two operating points for optimization

The constant power speed range (CPSR) is characterized by a ratio $\gamma$ between the maximum and base speeds given by (8).

$$
\gamma=\frac{\Omega_{m}}{\Omega_{b}}
$$

The optimization problem is formulated as (9).

$$
\begin{aligned}
\underset{X}{\operatorname{minimize}} & f(X)=\left\{\begin{array}{l}
\text { Total losses } \\
\text { Cost }
\end{array}\right. \\
\text { s.t. } & V_{\max } \leqslant 150[\mathrm{~V}] \\
& \theta_{\max } \leqslant 155\left[{ }^{\circ} \mathrm{C}\right] \\
& T=T^{*}[\mathrm{Nm}] \\
& \Omega=\Omega^{*}[\mathrm{rpm}]
\end{aligned}
$$

where $V_{\max }$ and $\theta_{\max }$ are maximum allowable voltage and winding temperature, respectively. $T$ and $\Omega$ are the machine torque and speed, $T^{*}$ and $\Omega^{*}$ are required torque and speed.

With the DESM type, nine geometry variables are chosen for the upper optimization level as marked in Fig. 6. With the PMSM type, only six variables $x_{1}, x_{4}$, $x_{5}, x_{6}, x_{7}$ and $x_{8}$ are used.

The width of the field winding windows are fixed, and the field windings are allowed to only change their heights $\left(x_{3}\right)$. In case the optimal solution does not prefer to use field windings, $x_{3}$ approaches zero. In order to avoid computation errors, the lower limit of $x_{3}$ is set to $0.05 \mathrm{~mm}$. Variable ranges are summarized in Table. I.

\section{B. Bi-level optimization approach}

In order to handle the optimization, a bi-level approach is used. The lower level is to find the optimal control
TABLE I

GEOMETRY VARIABLE RANGES

\begin{tabular}{llll}
\hline Variable & Description & Range $[\mathrm{mm}]$ & Prototype [mm] \\
\hline$x_{1}$ & Stack length & $30 \div 60$ & 40 \\
$x_{2}$ & Bridge thickness & $3 \div 12$ & 7 \\
$x_{3}$ & Field winding height & $0.05 \div 9$ & 9 \\
$x_{4}$ & Tooth width & $3 \div 6.5$ & 5.5 \\
$x_{5}$ & Tooth length & $10 \div 25$ & 16.5 \\
$x_{6}$ & Azimuth PM thickness & $4.5 \div 10$ & 6 \\
$x_{7}$ & Azimuth PM length & $10 \div 32$ & 24 \\
$x_{8}$ & Shaft radius & $10 \div 20$ & 17 \\
$x_{9}$ & Side PM thickness & $3 \div 10$ & 6 \\
\hline
\end{tabular}

set to minimize the total losses at each operating point. The upper level is to find machines with the lowest cost and smallest loss (found in the lower level). This approach implies that the lower level is a mono-objective optimization (only minimizing the total losses), and all constraints are dealt with at this level. Due to the presence of field windings in the DESM, three control variables representing field and armature currents are set. Whereas with the PMSM configuration, only two variables representing the armature current are presented. The upper level is a unconstrained multi-objective optimization. In this research, both optimization levels will use particle swarm optimization (PSO) technique [16], [17].

\section{RESULT AND DISCUSSION}

The machine cost is calculated based on normalized values by assuming unit cost (cost per kilogram active material) are 1, 6 and 7 for iron, copper and ferrite permanent magnet (PM), respectively [18]. The loss is the sum of the copper losses, core losses, and power electronics losses at the base (1547 rpm) and maximum speeds.

Targeting the flux controlling capabilities of both machine types, different CPSRs (i.e. different $\gamma$ ratios) will be examined. In this research, three values of $\gamma$ ranging from 3 to 5 will be evaluated.

Fig. 7 shows the comparison between optimal paretofronts of the two machine types.

As revealed in Fig. 7, the DESMs are capable of reducing the total losses compared to the PMSMs. This advantage is more obvious when increasing $\gamma$. This is due to the good flux weakening capability of the DESMs using two available options by field and armature windings, while a PMSM can only use negative $d$-axis currents from the armature windings. Strong field weakenings with a PMSM requires highly negative $d$-axis currents; therefore, increasing much the copper 

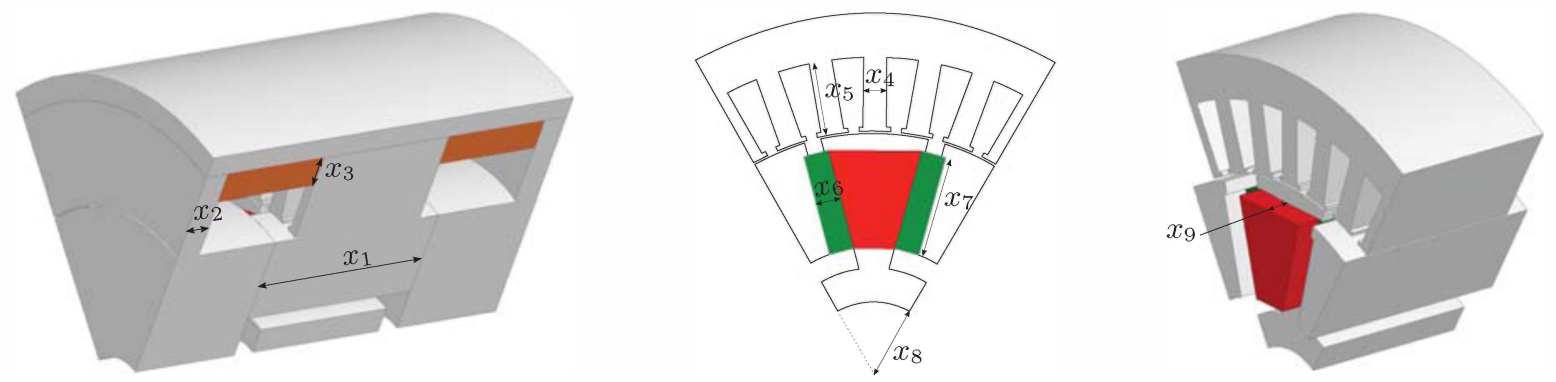

Fig. 6. Geometry variables: $x_{1}$ - stack length, $x_{2}$ - bridge thickness, $x_{3}$

- field winding height, $x_{4}$ - tooth width, $x_{5}$ - tooth length, $x_{6}$ - azimuth PM thickness, $x_{7}$-azimuth PM length, $x_{8}$ - shaft radius and $x_{9}$ side PM thickness.

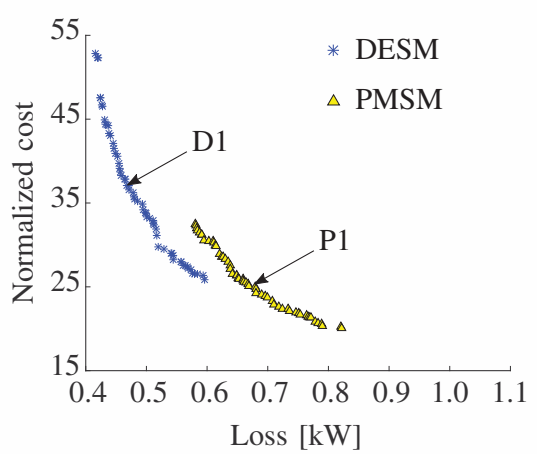

(a)

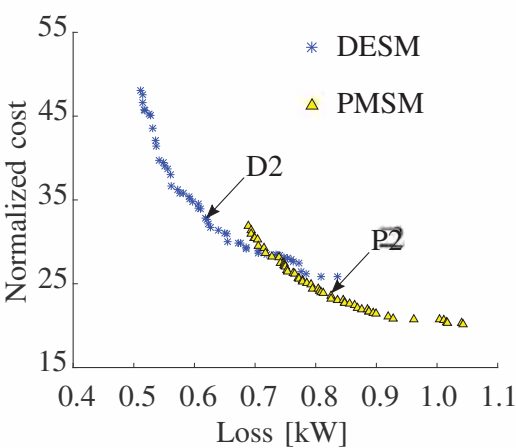

(b)

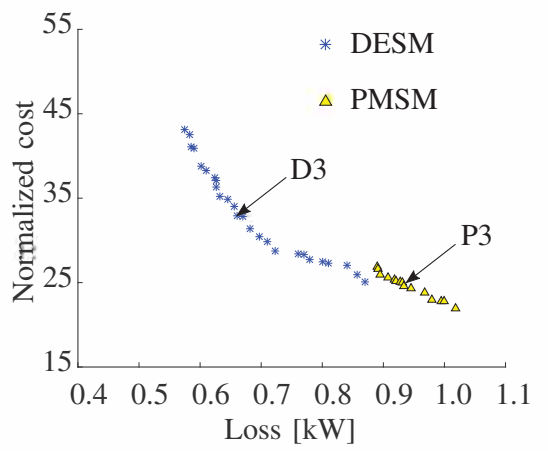

(c)

Fig. 7. Comparison results according to various speed ranges. (a) $\gamma=3$. (b) $\gamma=4$. (c) $\gamma=5$

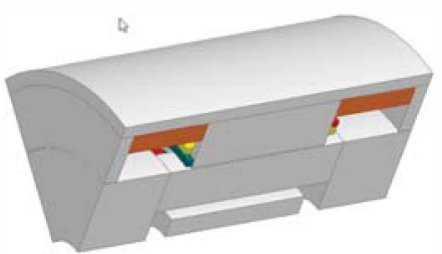

(a)

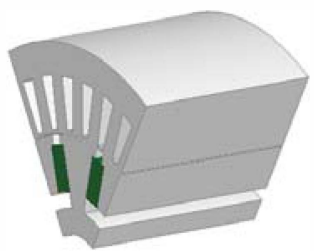

(d)

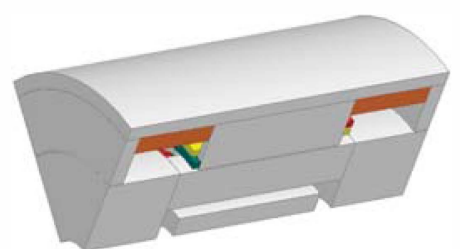

(b)

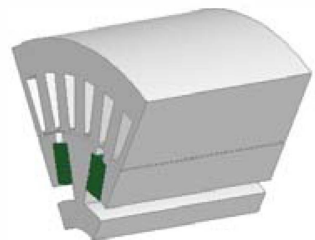

(e)

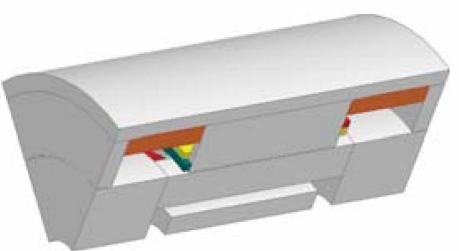

(c)

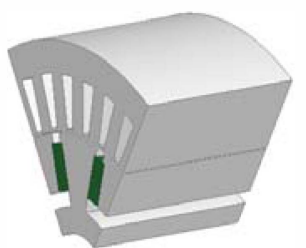

(f)

Fig. 8. Machines on the pareto-fronts: (a) D1. (b) D2. (c). D3. (d) P1. (e) P2. (f). P3

loss and possibly lead to a thermal limit violation as well. But using additional field windings, and moreover bigger volume would increase the machine cost as shown in Fig. 7 that DESM costs are higher in comparison with the ones of the PMSM type. In addition, PMSM machine type finds it difficult to reach very high speeds (partly proved as a limited number of machine found when $\gamma=5$ as in Fig. 7c)). In each case of $\gamma$ and machine type, a machine at the middle of the paretofront is extracted and shown in Fig. 8

Fig. 9 shows the field winding thickness (of the DESM type) variation along the pareto-front in the direction of increasing the total losses. As it can be seen, in order to reduce the total losses, a double excitation machine prefers to use more field windings.

Optimal current controls are shown in Fig. 10. Several 


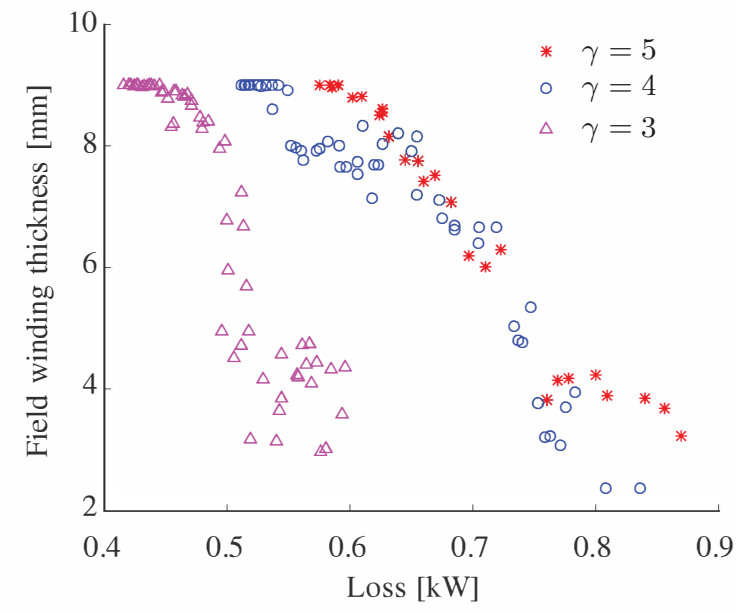

Fig. 9. Field winding thickness along the pareto-front (in increasing loss direction) according to various speed ranges

remarks would be observed:

1) A PMSM only uses the $d$-axis current to reduce the air-gap flux; therefore, a big amount of this current is required. Whereas with double excitation principle, a DESM can use both $d$-axis and field currents. As a result, it offers a good opportunity by a certain combination between these two currents to minimize the total losses.

2) There is no clear pattern for the trend of the current control in a DESM, and noises might be presented due to the combination of armature and field currents, since certain combinations might lead to a same or almost the same optimum.

3) DESM machines tend to use the field current to control the air-gap flux.

\section{Conluslion}

A comparison addressing the total losses and active material cost minimizations between a classical PM and double excitation machines has been presented. The comparisons was done at different speed ranges. The total losses were computed at the based and maximum speeds. DESM machines, with more complex structures due to the additional field windings, can provide flexible combinations between armature and field currents. This makes them capable of reducing the total losses at an expense of a bigger volume and more cost. The advantage of the field windings is more noticeable at very high speed, where a PMSM has to struggle keeping a low air-gap flux. In a perspective, a more elaborate comparison between these two machines on a specific application will be carried out.

\section{APPENDIX}

See Table. II.
TABLE II

DESM PROTOTYPE CONFIGURATION

\begin{tabular}{ll}
\hline Parameters & Value \\
\hline Number of phases & 3 \\
Number of turns per phase & 33 \\
Number of turns per field winding & 150 \\
Number of poles & 12 \\
Machine length & $115 \mathrm{~mm}$ \\
Outer stator diameter & $92 \mathrm{~mm}$ \\
Inner stator diameter & $57.5 \mathrm{~mm}$ \\
Number of slots & 36 \\
Air-gap length & $0.5 \mathrm{~mm}$ \\
PM residual flux density & $0.4 \mathrm{~T}$ (ferrite PM) \\
\hline
\end{tabular}

\section{REFERENCES}

[1] Y. Amara, L. Vido, M. Gabsi, E. Hoang, A. Hamid Ben Ahmed, and M. Lecrivain, "Hybrid excitation synchronous machines: Energy-efficient solution for vehicles propulsion," Vehicular Technology, IEEE Transactions on, vol. 58, no. 5, pp. 21372149, Jun 2009.

[2] J. Tapia, F. Leonardi, and T. Lipo, "Consequent-pole permanentmagnet machine with extended field-weakening capability," Industry Applications, IEEE Transactions on, vol. 39, no. 6, pp. 1704-1709, Nov 2003.

[3] J. S. Hsu, "Direct control of air-gap flux in permanent-magnet machines," IEEE Transactions on Energy Conversion, vol. 15, no. 4, pp. 361-365, Dec 2000.

[4] T.-K. Hoang, "Design optimization of double excitation synchronous machines in railway traction," $\mathrm{PhD}$ thesis, Université Paris-Saclay, Nov. 2016. [Online]. Available: https://hal.archives-ouvertes.fr/tel-01408271

[5] Z. Yang, F. Shang, I. P. Brown, and M. Krishnamurthy, "Comparative study of interior permanent magnet, induction, and switched reluctance motor drives for ev and hev applications," IEEE Transactions on Transportation Electrification, vol. 1, no. 3, pp. 245-254, Oct 2015.

[6] P. Lazari, J. Wang, and L. Chen, "A computationally efficient design technique for electric-vehicle traction machines," IEEE Transactions on Industry Applications, vol. 50, no. 5, pp. 32033213, Sept 2014.

[7] A. Vagati, G. Pellegrino, and P. Guglielmi, "Comparison between spm and ipm motor drives for ev application," in The XIX International Conference on Electrical Machines - ICEM 2010, Sept 2010, pp. 1-6.

[8] Y. Dai, L. Song, and S. Cui, "Development of pmsm drives for hybrid electric car applications," IEEE Transactions on Magnetics, vol. 43, no. 1, pp. 434-437, Jan 2007.

[9] E. Hoang, M. Lecrivain, S. Hlioui, and M. Gabsi, "Hybrid excitation synchronous permanent magnets synchronous machines optimally designed for hybrid and full electrical vehicle," in Power Electronics and ECCE Asia (ICPE ECCE), 2011 IEEE 8th International Conference on, May 2011, pp. 153-160.

[10] N. Patin, L. Vido, E. Monmasson, J. P. Louis, M. Gabsi, and M. Lecrivain, "Control of a hybrid excitation synchronous generator for aircraft applications," IEEE Transactions on Industrial Electronics, vol. 55, no. 10, pp. 3772-3783, Oct 2008.

[11] D. Fodorean, A. Djerdir, I. A. Viorel, and A. Miraoui, "A double excited synchronous machine for direct drive applica- 


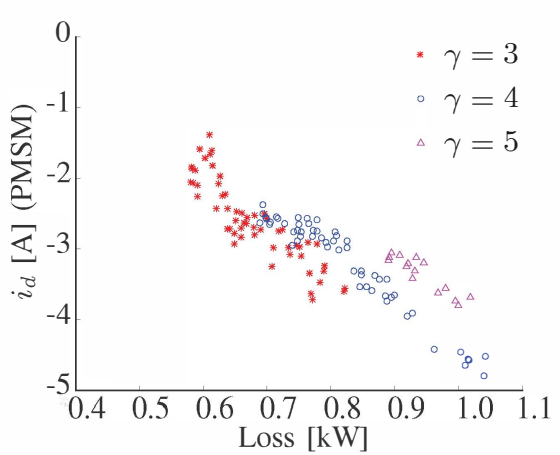

(a)

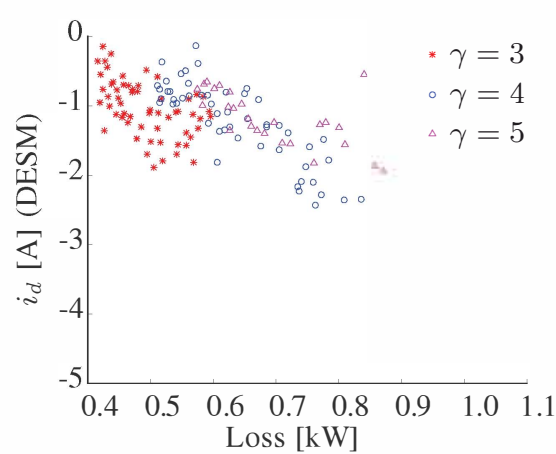

(b)

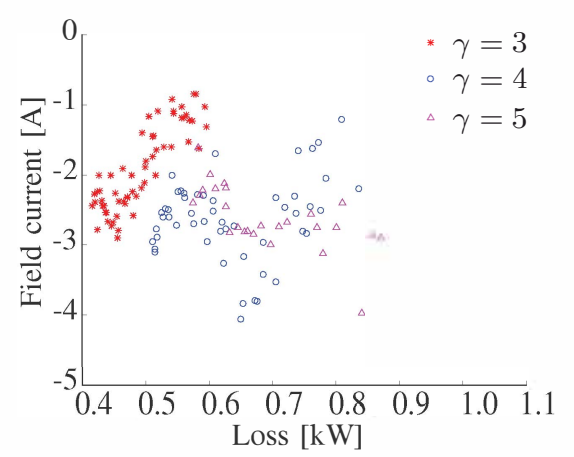

(c)

Fig. 10. Current controls along the pareto-front (in increasing loss direction). a) $d$-axis current in PMSM. b) $d$-axis current in DESM. c) Field current in DESM

tion: Design and prototype tests," Energy Conversion, IEEE Transactions on, vol. 22, no. 3, pp. 656-665, Sept 2007.

[12] L. Vido, M. Gabsi, M. Lecrivain, Y. Amara, and F. Chabot, "Homopolar and bipolar hybrid excitation synchronous machines," in Electric Machines and Drives, 2005 IEEE International Conference on, May 2005, pp. 1212-1218.

[13] K. Hoang, L. Vido, F. Gillon, and M. Gabsi, "Modeling of double excitation synchronous motors using nodal based generalized equivalent magnetic circui." ISEF, September 2015.

[14] J. E. Vrancik, "Prediction of windage power loss in alternators," NASA, Tech. Rep., October 1968

[15] M. Bierhoff and F. Fuchs, "Semiconductor losses in voltage source and current source igbt converters based on analytical derivation," in Power Electronics Specialists Conference, 2004.
PESC 04. 2004 IEEE 35th Annual, vol. 4, 2004, pp. 2836-2842. [16] J. Aubry, H. B. Ahmed, and B. Multon, "Bi-objective sizing optimization of a pm machine drive on an operating profile," in Electrical Machines (ICEM), 2010 XIX International Conference on, Sept 2010, pp. 1-7.

[17] J. Aubry, "Optimisation du dimensionnement d'une chaîne de conversion électrique directe incluant un système de lissage de production par supercondensateurs. application au houlogénérateur searev," Thèse, École normale supérieure de Cachan - ENS Cachan, Nov. 2011.

[18] A. Saxena, "Performance and cost comparison of pm bldc motors for ceiling fan," in Power Electronics, Drives and Energy Systems (PEDES), 2014 IEEE International Conference on, Dec 2014, pp. 1-5. 